\title{
Enzyme-Catalyzed Synthesis of Furanosyl Nucleotides
}

\author{
Shannon C. Timmons,${ }^{\S}$ Joseph P. M. Hui, ${ }^{\ddagger}$ Jessica L. Pearson, ${ }^{\dagger}$ Pauline Peltier, ${ }^{\xi}$ Richard Daniellou, ${ }^{\xi}$ \\ Caroline Nugier-Chauvin, ${ }^{\xi}$ Evelyn C. Soo, ${ }^{\ddagger}$ Ray T. Syvitski, ${ }^{\ddagger}$ Vincent Ferrières, ${ }^{\xi}$ and David L. \\ Jakeman ${ }^{\dagger \S *}$ \\ ${ }^{\S}$ Department of Chemistry, Dalhousie University, Halifax, Nova Scotia, Canada, B3H $4 \mathrm{~J} 3$. \\ ${ }^{*}$ MS Metabolomics Group, NRC Institute for Marine Biosciences, 1411 Oxford Street, Halifax, Nova Scotia, Canada, \\ B3H $3 Z 1$. \\ ${ }^{\xi}$ Organic and Supramolecular Chemistry, Ecole Nationale Supérieure de Chimie de Rennes, CNRS, Avenue du \\ General Leclerc, F-35700 Rennes, France. \\ ${ }^{\dagger}$ College of Pharmacy, 5968 College St., Dalhousie University, Halifax, Nova Scotia, Canada, B3H 3J5.
}

\section{Supporting Information Table of Contents:}

Enzyme-Catalyzed Synthesis of Furanosyl Nucleotides ................................................................ 1

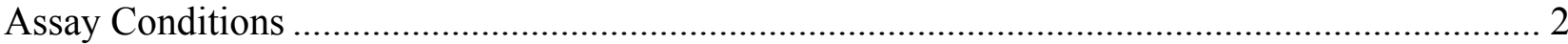

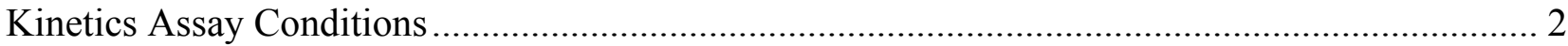

Hydrophilic Interaction Liquid Chromatography-Electrospray Ionization Tandem Mass

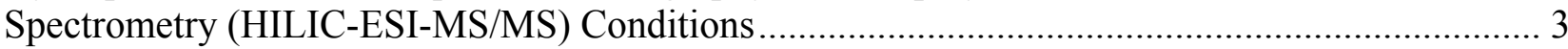

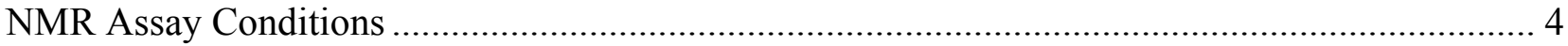

Figure S1. Nucleotidylyltransferase Cps2L is stereoselective for sugar-1-phosphate substrates..... 5

Table S1. Percentage conversions of dTTP to sugar nucleotide products using Cps2L.................... 6

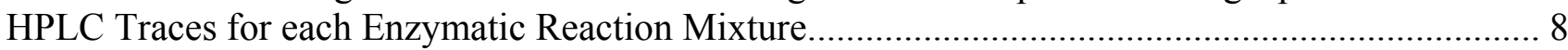

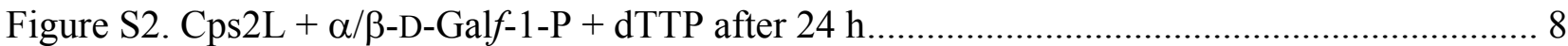

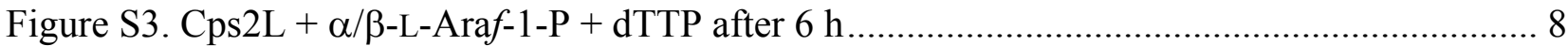

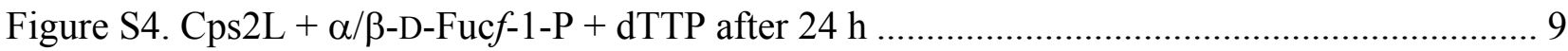

Figure S5. Cps2L + 6-Deoxy-6-Fluoro- $\alpha / \beta$-D-Galf-1-P + dTTP after $24 \mathrm{~h} \mathrm{...................................} 9$

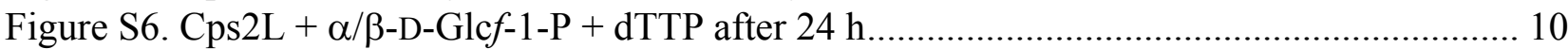

HILIC-ESI-MS/MS EPI Scan Data of Enzyme-Catalyzed Preparation of Sugar Nucleotides ........... 11

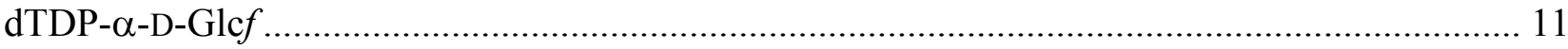

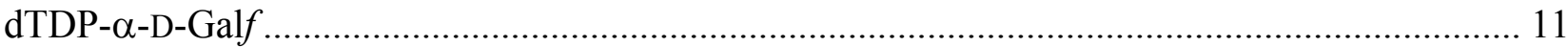

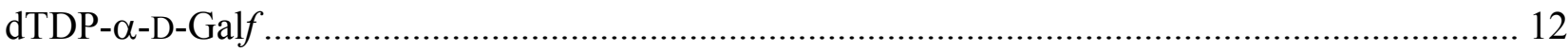

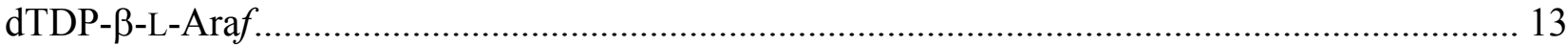

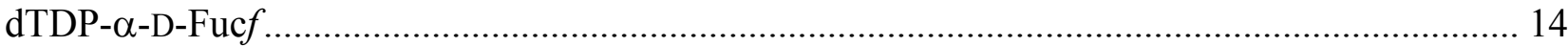

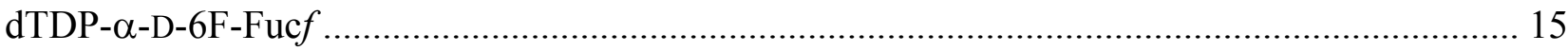

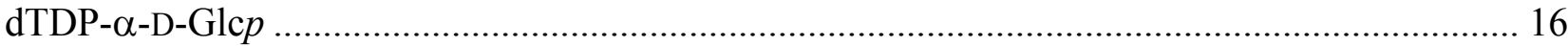

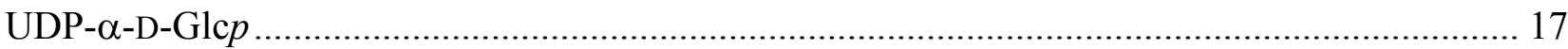

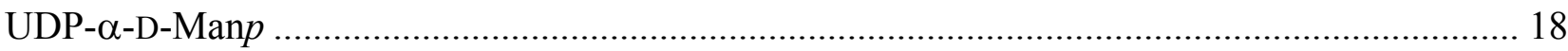

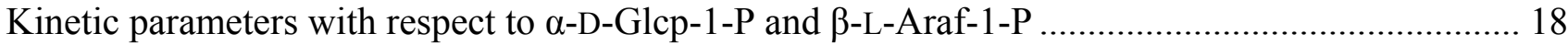

Kinetic parameters with respect to $\alpha$-D-Glcp-1-P and $\beta$-L-Araf-1-P ……......................................... 19

Figure S7. Michaelis-Menten and Lineweaver-Burk plots for Gle $p-1-\mathrm{P}$...................................... 19

Figure S8. Michaelis-Menten and Lineweaver-Burk plots for Araf-1-P .................................... 20 


\section{Assay Conditions}

Enzymatic reactions containing $1.0 \mathrm{mM}$ dTTP, $2.0 \mathrm{mM}$ furanose-1-phosphate, $2.2 \mathrm{mM} \mathrm{MgCl}$, and 0.5 EU inorganic pyrophosphatase were initiated by the addition of 10 EU Cps2L glucopyranosyl-1phosphate thymidylyltransferase (Streptococcus pneumoniae R6) in Tris-HCl buffer (39 $\mathrm{mM}$ final buffer concentration, $50 \mu \mathrm{L}$ reaction volume). The enzymatic reactions were conducted at $22{ }^{\circ} \mathrm{C}$ and reaction progress was monitored at 1, 6, 12, 18, and $24 \mathrm{~h}$ by HPLC. Enzymatic reaction aliquots (10 $\mu \mathrm{L})$ were quenched with $\mathrm{HPLC}$ grade $\mathrm{MeOH}(10 \mu \mathrm{L})$ and centrifuged $(5 \min$ at $12,000 \times g)$ to precipitate denatured enzymes prior to HPLC analysis.

Note: (i) that uncorrected percentage conversions refer to analysis of only NTP and sugar nucleotide product peak areas while corrected conversions take into account the degradation of sugar nucleotide products over the given time period (as determined by comparison with reactions containing no thymidylyltransferase under identical conditions). Assays were conducted at $22{ }^{\circ} \mathrm{C}$ instead of $37{ }^{\circ} \mathrm{C}$ to help minimize sugar nucleotide degradation.

(ii) that the HPLC method used to determine the conversions is documented in the Supporting Information of Timmons, S. C.; Mosher, R. H.; Knowles, S. A.; Jakeman, D. L. Org. Lett. 2007, 9, $857-860$.

\section{Kinetics Assay Conditions}

$200 \mu \mathrm{L}$ enzymatic reactions containing $1.0 \mathrm{mM}$ dTTP, $2.2 \mathrm{mM} \mathrm{MgCl}_{2}, 2$ EU inorganic pyrophosphatase, $100 \mu \mathrm{M}$ thymidine and either $50 \mathrm{mM}, 75 \mathrm{mM}, 100 \mathrm{mM}, 200 \mathrm{mM}$ or $300 \mathrm{mM} \alpha$-Dglucopyranose-1-phosphate or $\beta$-L-arabinofuranose-1-phosphate (accounting for the $\alpha / \beta$ mixture) were initiated by the addition of $0.102 \mu \mathrm{M}$ Cps2L ( $0.001 \mathrm{EU})$ or $128 \mu \mathrm{M}$ Cps2L (1.3 EU) for glucopyranose1-phosphate and $\beta$-L-arabinofuranose-1-phosphate, respectively. The enzymatic reactions were conducted at $37^{\circ} \mathrm{C}$ and monitored at $1,2,4,6$, and 10 minutes ( $\alpha$-D-glucopyranose-1-phopshate) or 5 , 
$10,15,30$, and 45 minutes ( $\beta$-L-arabinofuranose-1-phopshate). Enzymatic reaction aliquots $(40 \mu \mathrm{L})$ were quenched with HPLC grade $\mathrm{MeOH}(40 \mu \mathrm{L})$ and centrifuged (5 min at 12,000 x $g$ ) to precipitate denatured enzymes prior to HPLC analysis. The HPLC method used to determine conversions is as

described in the Supporting Information of Timmons, S. C.; Mosher, R. H.; Knowles, S. A.; Jakeman, D. L. Org. Lett. 2007, 9, 857-860 except using a linear gradient from 80:20 A/B to 75:35 A/B over 9.0 min to $40: 60 \mathrm{~A} / \mathrm{B}$ at $10.0 \mathrm{~min}$ followed by a plateau at $40: 60 \mathrm{~A} / \mathrm{B}$ from 10.0 to $11.0 \mathrm{~min}$ at $1.0 \mathrm{~mL} / \mathrm{min}$. Final concentrations of the sugar nucleotides were determined by comparing the product peak area to that of a thymidine internal standard $(100 \mu \mathrm{M}$ concentration in the reaction mixture). Initial rates were determined by plotting concentration of sugar nucleotides versus time. Michaelis-Menten and Lineweaver-Burk plots were fitted using GraFit 5.0 software.

\section{Hydrophilic Interaction Liquid Chromatography-Electrospray lonization Tandem Mass Spectrometry (HILIC-ESI-MS/MS) Conditions}

An Agilent 1100 LC system was coupled to the QTRAP 4000 mass spectrometer for the HILIC-ESIMS/MS experiments. The samples were separated on a TSK-gel Amide 80 HILIC column (4.6 mm I.D. x $25 \mathrm{~cm}$, Tosoh Bioscience) by gradient elution. The mobile phase comprised of an initial condition of MeCN: $6.5 \mathrm{mM}$ ammonium acetate $\mathrm{pH} 5.5$ 80:20 (v/v) and was ramped linearly to 70:30 (v/v) in $10 \mathrm{~min}$ and then held at this composition for $5 \mathrm{~min}$. A flow-rate of $1 \mathrm{~mL} / \mathrm{min}$ was employed for the separations and reduced to $200 \mu \mathrm{L} / \mathrm{min}$ before introducing to the mass spectrometer. ESIMS/MS analysis in the enhanced product ion (EPI) mode was performed on an Applied BiosystemsMDS SCIEX hybrid triple quadrupole linear ion trap (QTRAP 4000) mass spectrometer equipped with

a Turbo V source for electrospray ionization. The mass spectrometer settings were: ionspray voltage $4.3 \mathrm{kV}$; mass range Q3 m/z 100-600; scan speed $1000 \mathrm{amu} / \mathrm{sec}$; trap fill time was set to dynamic; Q1 and Q3 were set to unit resolution'. All acquisitions were made in the negative mode. 


\section{NMR Assay Conditions}

Solutions containing $0.05 \mu \mathrm{mol} \mathrm{dTTP}, 0.1 \mu \mathrm{mol}$ sugar-1-phosphate, and $0.11 \mu \mathrm{mol} \mathrm{MgCl}_{2}$ were lyophilized. Enzymatic reactions were initiated by the addition of 20 EU Cps2L nucleotidylyltransferase in $20 \mu \mathrm{L}$ Tris- $\mathrm{d}_{11}-\mathrm{DCl}$ buffer $\left(50 \mathrm{mM}, \mathrm{pH} 7.6, \mathrm{pH}\right.$ uncorrected for $\left.\mathrm{D}_{2} \mathrm{O}\right)$ for final reactant concentrations of $2.5 \mathrm{mM}$ dTTP, $5.0 \mathrm{mM}$ sugar-1-phosphate, $5.5 \mathrm{mM} \mathrm{MgCl}_{2}$. The enzymatic reaction mixtures were incubated at $25{ }^{\circ} \mathrm{C}$ and analyzed using a Bruker Avance/DRX-500 high-resolution spectrometer with a MicroProbe located at the National Research Council Canada Institute for Marine Biosciences in Halifax. 


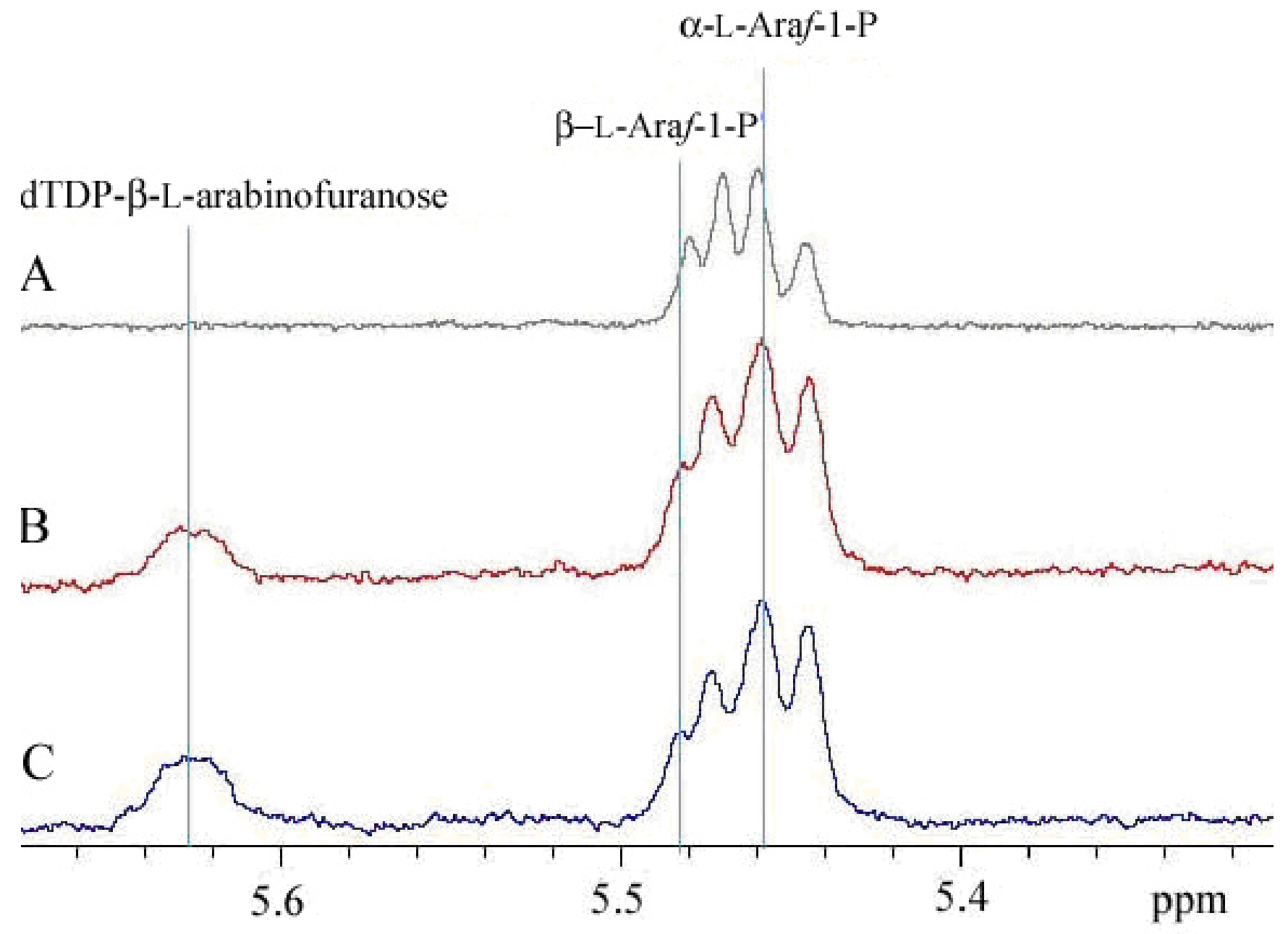

Figure S1. Nucleotidylyltransferase Cps2L is stereoselective for sugar-1phosphate substrates

Spectrum A shows the reaction containing $\alpha / \beta$-L-arabinofuranosyl-1-phosphate prior to the addition of enzyme. Spectra B and $\mathrm{C}$ show the reaction mixture at 7 and 21 hours, respectively, illustrating the appearance of the anomeric signal for dTDP- $\alpha$-L-arabinofuranose $(5.62 \mathrm{ppm})$ in conjunction with the disappearance of the anomeric signal for $\beta$-L-Araf-1-P (5.48 ppm) whilst the signal for $\alpha$-L-Araf-1-P (5.46 ppm) remains constant. 


\section{Table S1. Percentage conversions of dTTP to sugar nucleotide products using Cps2L}

\begin{tabular}{|c|c|c|c|c|c|}
\hline NTP & $\begin{array}{l}\text { furanose-1-phosphate } \\
(\alpha / \beta \text { ratio })^{*}\end{array}$ & $\begin{array}{l}\text { assay time } \\
(\mathrm{h})\end{array}$ & $\begin{array}{c}\% \\
\text { conversion }^{\ddagger} \\
\text { (uncorrected) }\end{array}$ & $\begin{array}{c}\% \\
\text { conversion }^{\dagger} \\
\text { (corrected) }\end{array}$ & $\begin{array}{c}\text { dTDP- } \\
\text { furanose } \\
\text { retention time }\end{array}$ \\
\hline dTTP & $\alpha / \beta-D-G a l f-1-P(1.2 / 1.0)$ & 1 & 19 & 8 & 5.807 \\
\hline dTTP & $\alpha / \beta-D-G a l f-1-P(1.2 / 1.0)$ & 6 & 36 & 22 & 5.821 \\
\hline dTTP & $\alpha / \beta-D-G a l f-1-P(1.2 / 1.0)$ & 12 & 52 & 31 & 5.824 \\
\hline dTTP & $\alpha / \beta-D-G a l f-1-P(1.2 / 1.0)$ & 18 & 63 & 33 & 5.821 \\
\hline dTTP & $\alpha / \beta-D-G a l f-1-P(1.2 / 1.0)$ & 24 & 81 & 40 & 5.835 \\
\hline dTTP & $\alpha / \beta$-L-Araf-1-P (1.0/1.3) & 1 & 47 & 39 & 5.913 \\
\hline dTTP & $\alpha / \beta$-L-Araf-1-P (1.0/1.3) & 6 & 74 & $58\left(66^{* *}\right)$ & 5.911 \\
\hline dTTP & $\alpha / \beta$-L-Araf-1-P (1.0/1.3) & 12 & 83 & 55 & 5.925 \\
\hline dTTP & $\alpha / \beta$-L-Araf-1-P (1.0/1.3) & 18 & 89 & 49 & 5.937 \\
\hline dTTP & $\alpha / \beta$-L-Araf-1-P (1.0/1.3) & 24 & 91 & 42 & 5.942 \\
\hline dTTP & $\alpha / \beta$-D-Fucf-1-P (1.5/1.0) & 1 & 20 & 11 & 6.010 \\
\hline dTTP & $\alpha / \beta$-D-Fucf-1-P (1.5/1.0) & 6 & 34 & 23 & 6.005 \\
\hline dTTP & $\alpha / \beta$-D-Fucf-1-P (1.5/1.0) & 12 & 45 & 31 & 6.010 \\
\hline dTTP & $\alpha / \beta$-D-Fucf-1-P (1.5/1.0) & 18 & 56 & 37 & 5.982 \\
\hline dTTP & $\alpha / \beta$-D-Fucf-1-P (1.5/1.0) & 24 & 66 & 41 & 6.011 \\
\hline dTTP & $\begin{array}{c}\text { 6-Deoxy-6-Fluoro- } \alpha / \beta \text {-D-Galf-1-P } \\
(1.7 / 1.0)\end{array}$ & 1 & 16 & 8 & 6.012 \\
\hline dTTP & $\begin{array}{c}\text { 6-Deoxy-6-Fluoro- } \alpha / \beta \text {-D-Galf-1-P } \\
(1.7 / 1.0) \\
\text { 6-Deoxy-6-Fluoro- } \alpha / \beta-D-G a l f-1-P\end{array}$ & 6 & 21 & 11 & 6.008 \\
\hline dTTP & $(1.7 / 1.0)$ & 12 & 29 & 14 & 6.012 \\
\hline dTTP & $\begin{array}{l}\text { 6-Deoxy-6-Fluoro- } \alpha / \beta \text {-D-Galf-1-P } \\
(1.7 / 1.0)\end{array}$ & 18 & 38 & 17 & 6.025 \\
\hline dTTP & $\begin{array}{l}\text { 6-Deoxy-6-Fluoro- } \alpha / \beta-D-G a l f-1-P \\
(1.7 / 1.0)\end{array}$ & 24 & 45 & 19 & 6.015 \\
\hline dTTP & $\alpha / \beta$-D-Glcf-1-P (1.9/1.0) & 1 & 15 & 6 & 5.726 \\
\hline dTTP & $\alpha / \beta$-D-Glcf-1-P (1.9/1.0) & 6 & 19 & 6 & 5.725 \\
\hline dTTP & $\alpha / \beta$-D-Glcf-1-P (1.9/1.0) & 12 & 25 & 6 & 5.729 \\
\hline dTTP & $\alpha / \beta$-D-Glcf-1-P (1.9/1.0) & 18 & 34 & 7 & 5.747 \\
\hline dTTP & $\alpha / \beta$-D-Glcf-1-P (1.9/1.0) & 24 & 42 & 7 & 5.764 \\
\hline
\end{tabular}

"Furanose-1-phosphates $\alpha / \beta$-D-Galf-1-P, $\alpha / \beta$-D-Fucf-1-P, and $\alpha / \beta$-D-Glcf-1-P were synthesized according to the methods described in Euzen, R.; Ferrières, V.; Plusquellec, D. J. Org. Chem. 2005, 70, 
847-855. The preparation of 6-Deoxy-6-Fluoro- $\alpha / \beta$-D-Galf-1-P and $\alpha / \beta$-D-Fucf-1-P were accomplished in a similar manner and will be reported in due course elsewhere. **Accounting for $\alpha / \beta$ ratio. Percentage conversion $=\left(A_{P} /\left(A_{\mathrm{P}}+A_{\mathrm{T}}\right)\right) \times 100$, where $A_{\mathrm{P}}=\mathrm{dTDP}$-furanose product peak area and $A_{\mathrm{T}}=$ dTTP peak area. ${ }^{\dagger}$ Percentage conversion $=\left(A_{\mathrm{P}} /\left(A_{\mathrm{P}}+A_{\mathrm{T}}+A_{\mathrm{D}}\right)\right) \times 100$, where $A_{\mathrm{P}}=\mathrm{dTDP}$-furanose product peak area, $A_{\mathrm{T}}=\mathrm{dTTP}$ peak area, and $A_{\mathrm{D}}=$ degradation product peak area.

Please note that lines highlighted in yellow refer to the time points at which the highest corrected conversion to dTDP-furanose was observed. The HPLC traces for these time points are presented below. 


\section{HPLC Traces for each Enzymatic Reaction Mixture}

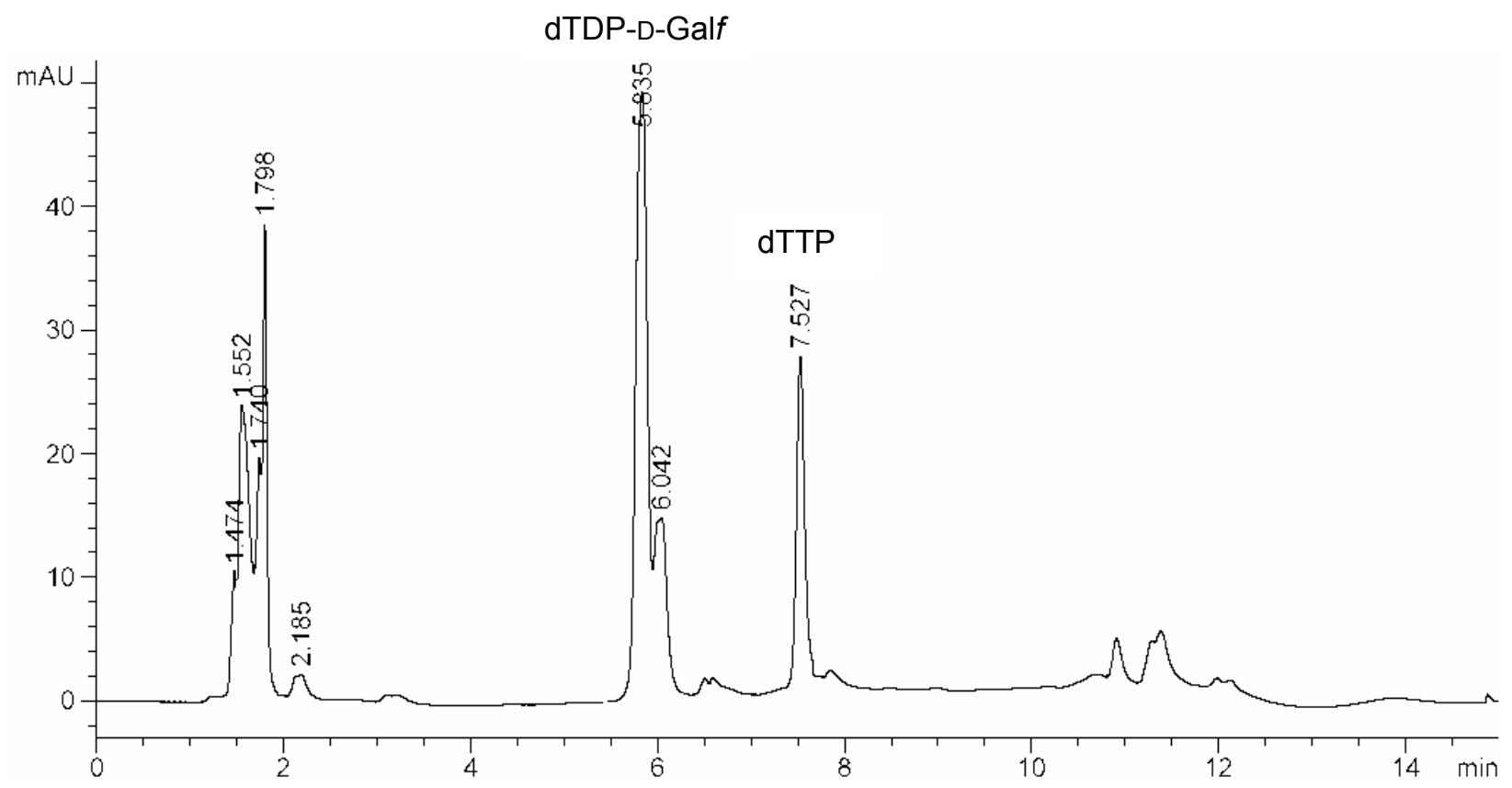

Figure S2. Cps2L + $\alpha / \beta-D-G a l f-1-P+d T T P$ after $24 h$

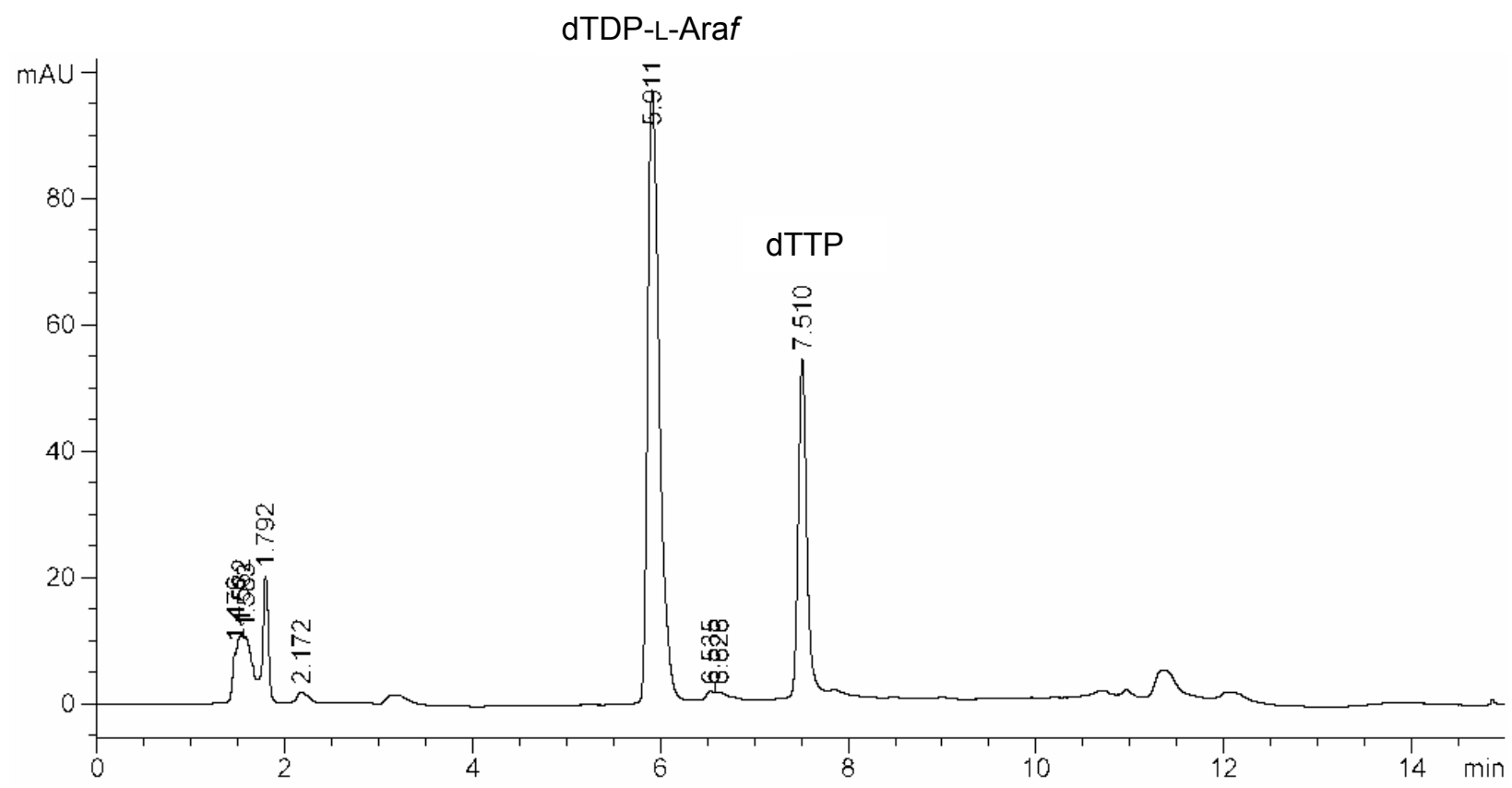

Figure S3. Cps2L + $\alpha / \beta-L-A r a f-1-P+d T T P$ after $6 \mathrm{~h}$ 


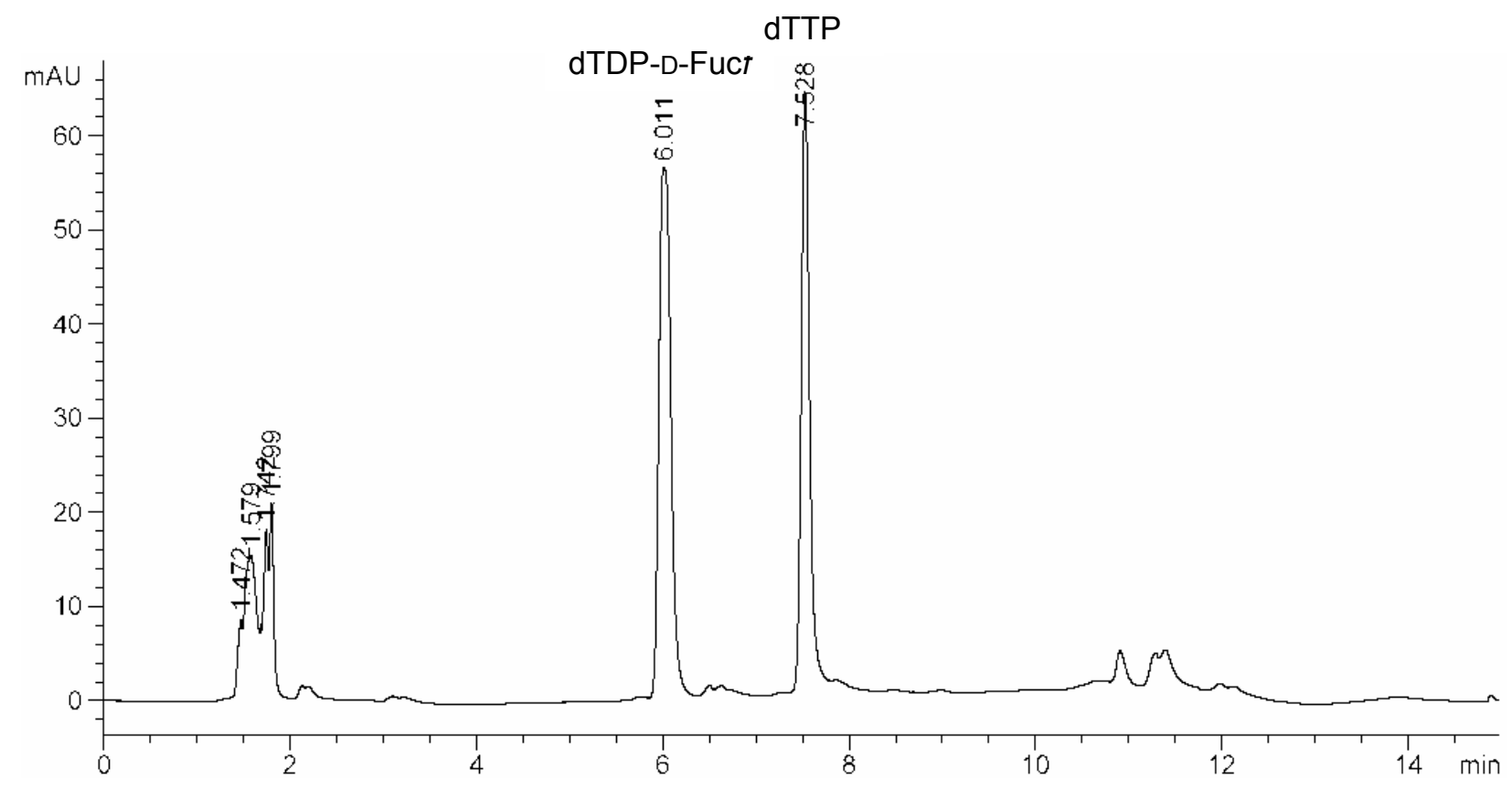

Figure S4. Cps2L + $\alpha / \beta-D-F u c f-1-P+d T T P$ after 24 h

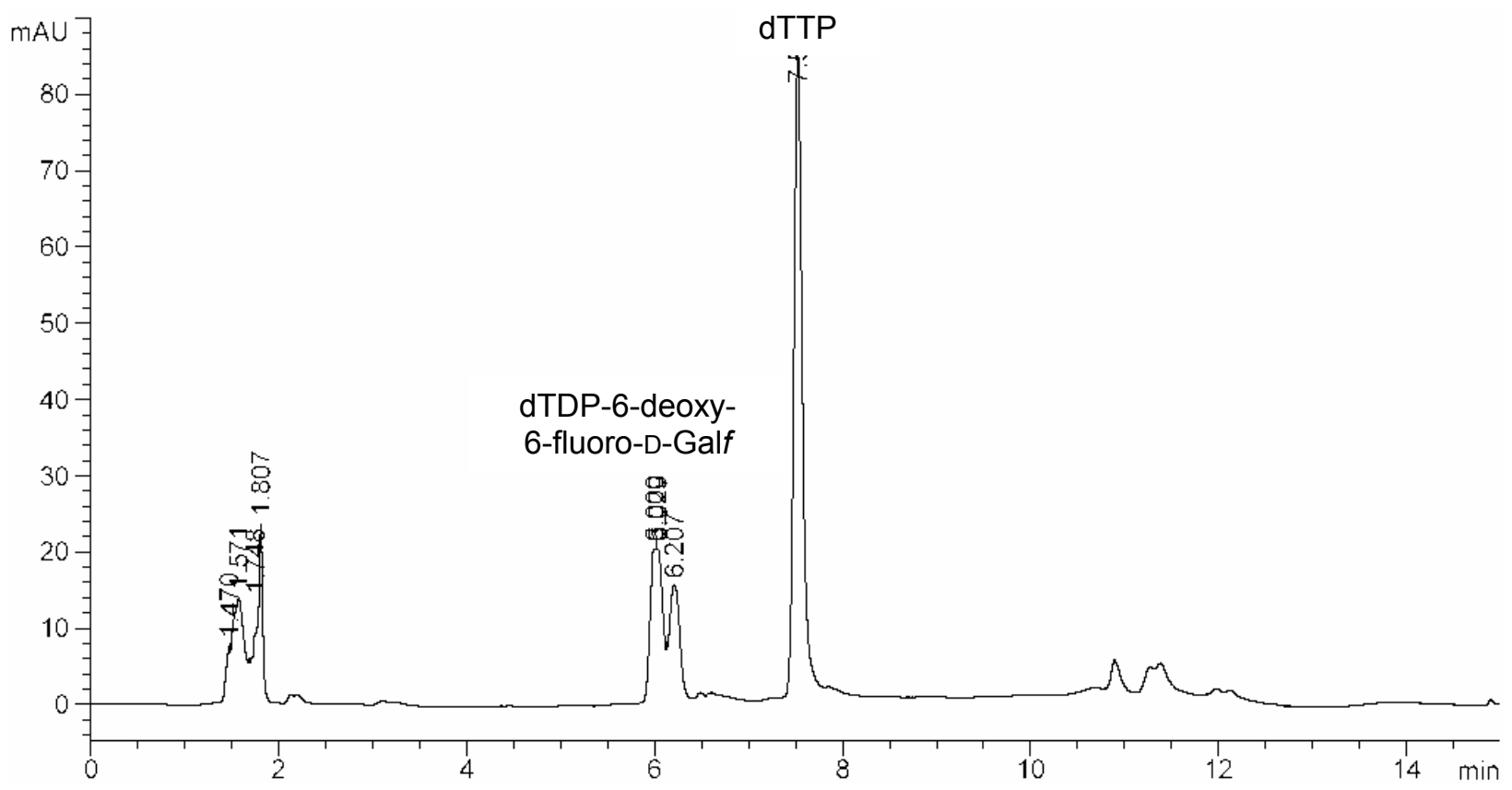

Figure S5. Cps2L + 6-Deoxy-6-Fluoro- $\alpha / \beta-D-G a l f-1-P+d T T P$ after 24 h 


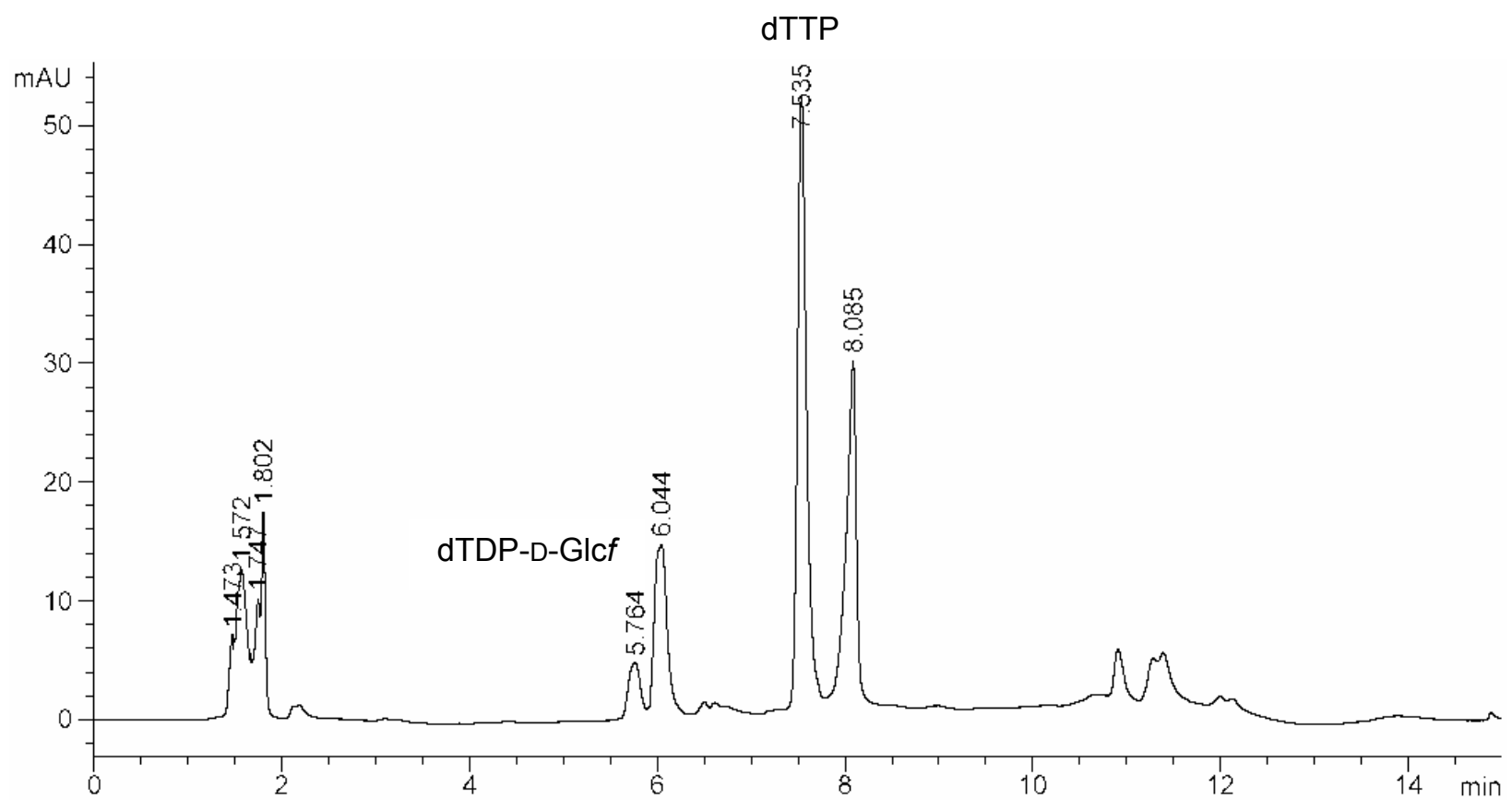

Figure S6. Cps2L + $\alpha / \beta-D-G I c f-1-P+d T T P$ after $24 h$ 


\section{HILIC-ESI-MS/MS EPI Scan Data of Enzyme-Catalyzed Preparation of Sugar Nucleotides}

\section{dTDP- $\alpha-D-G I c f$}
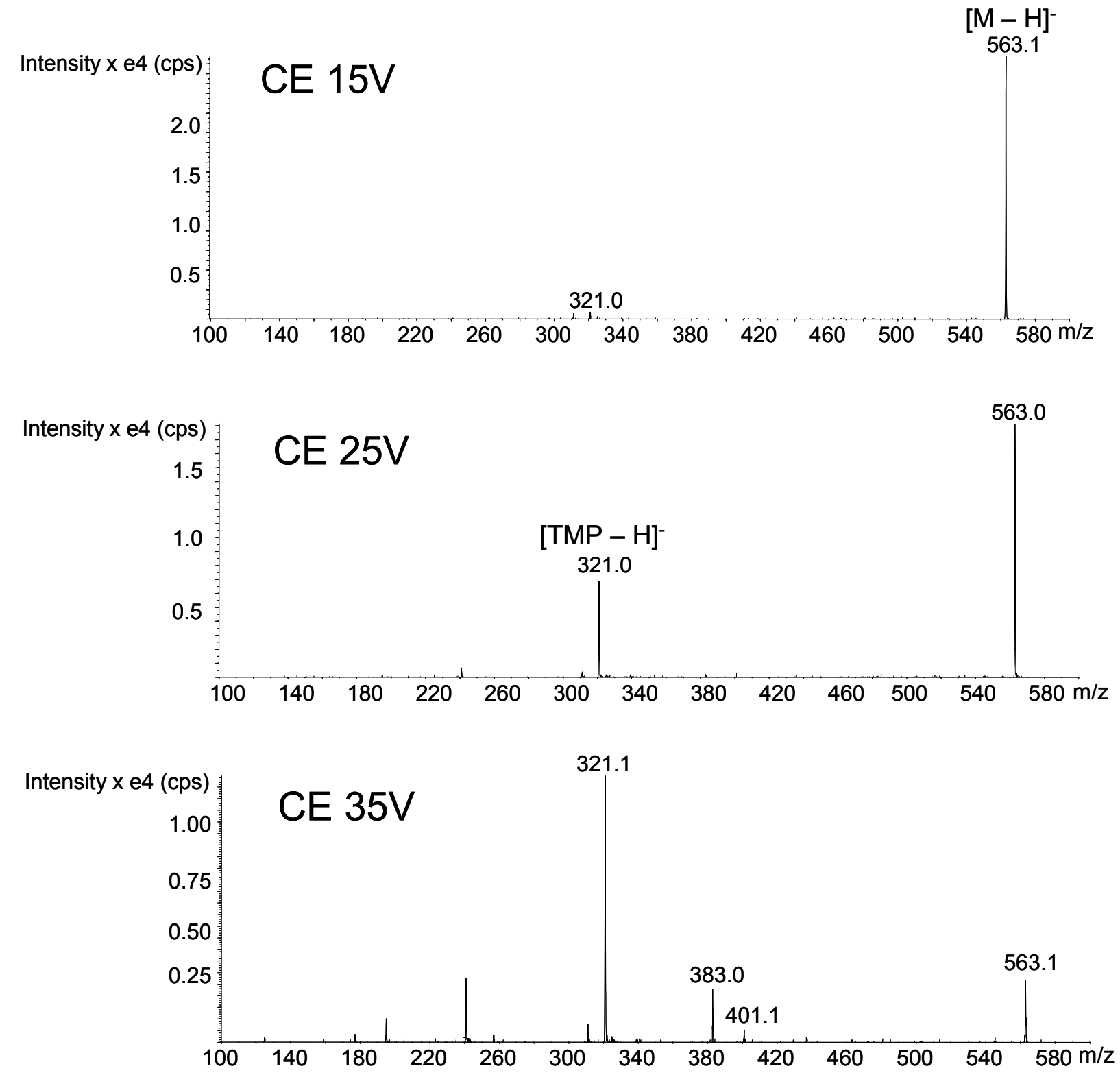


\section{dTDP- $\alpha-D-G a l f$}
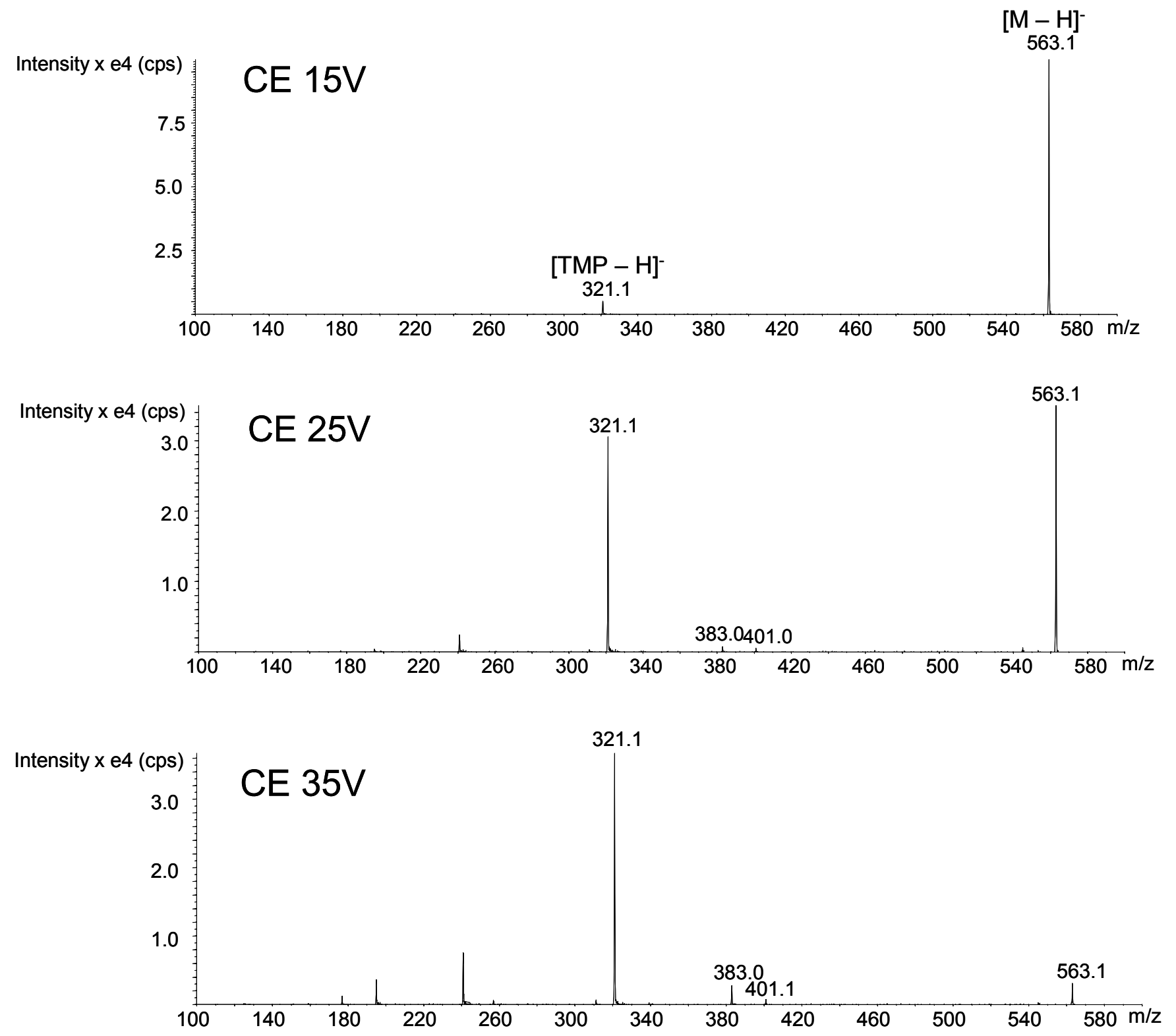


\section{dTDP- $\beta$-L-Araf}
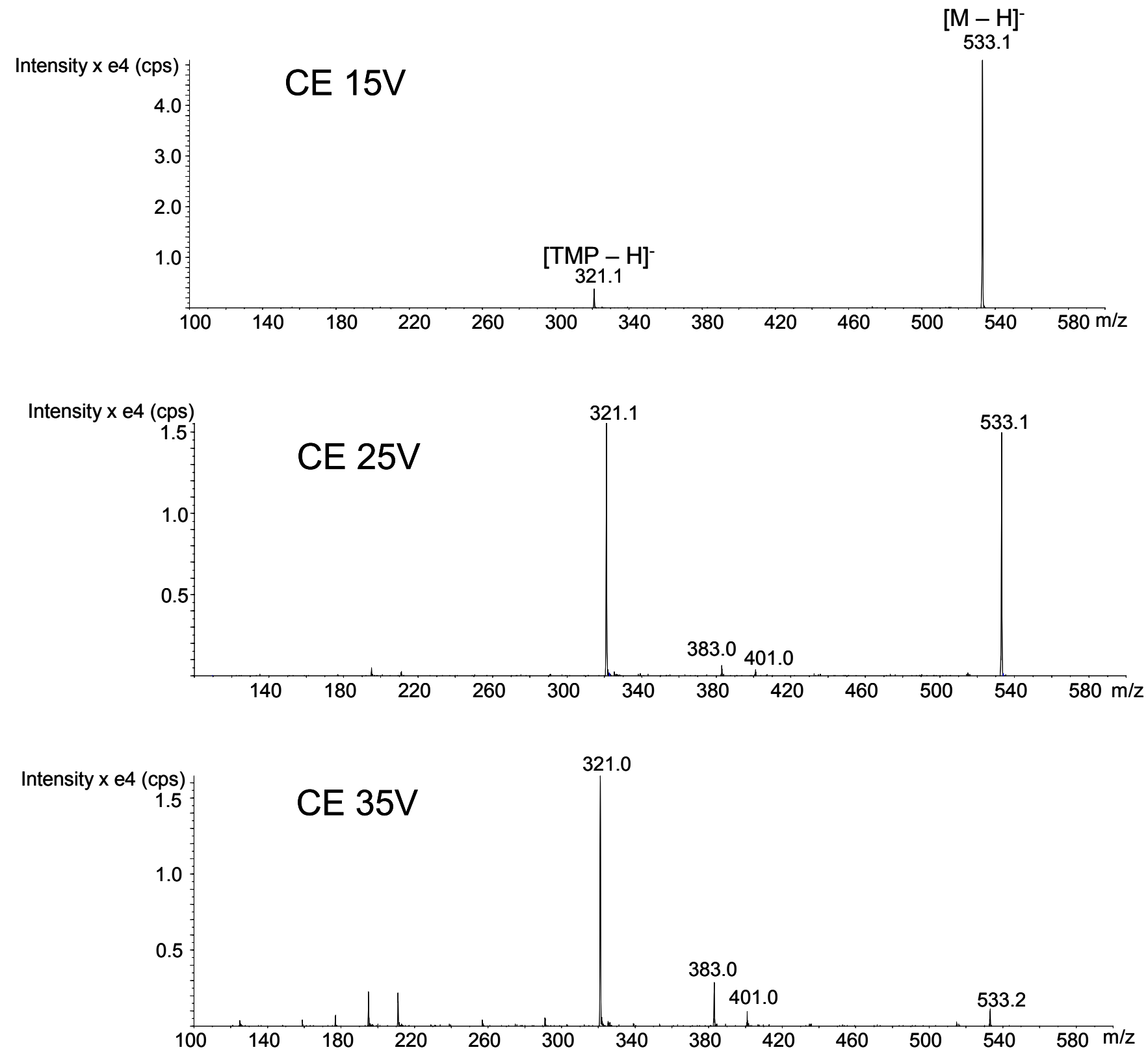


\section{dTDP- $\alpha-D-F u c f$}
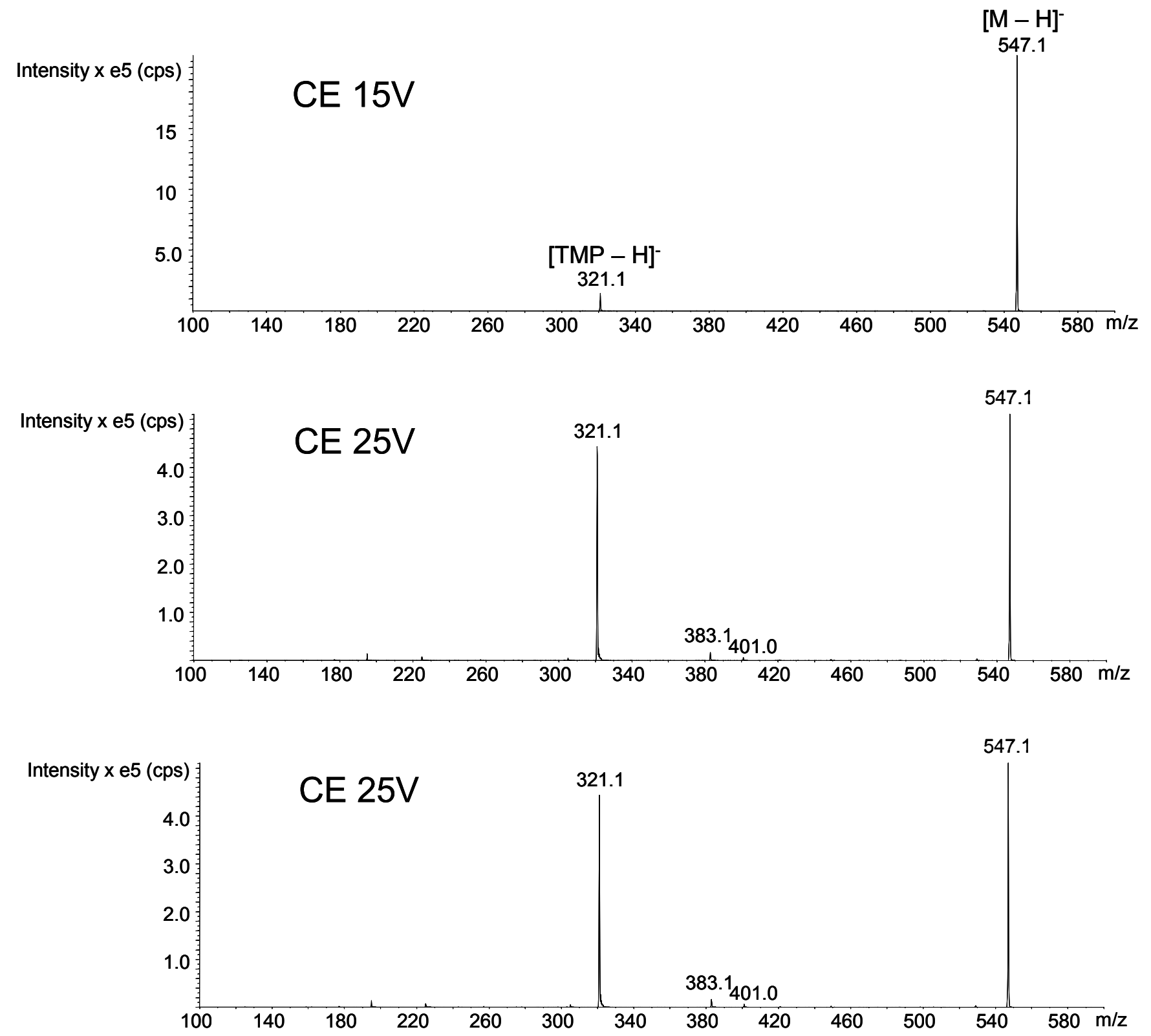


\section{dTDP- $\alpha-D-6 F-F u c f$}
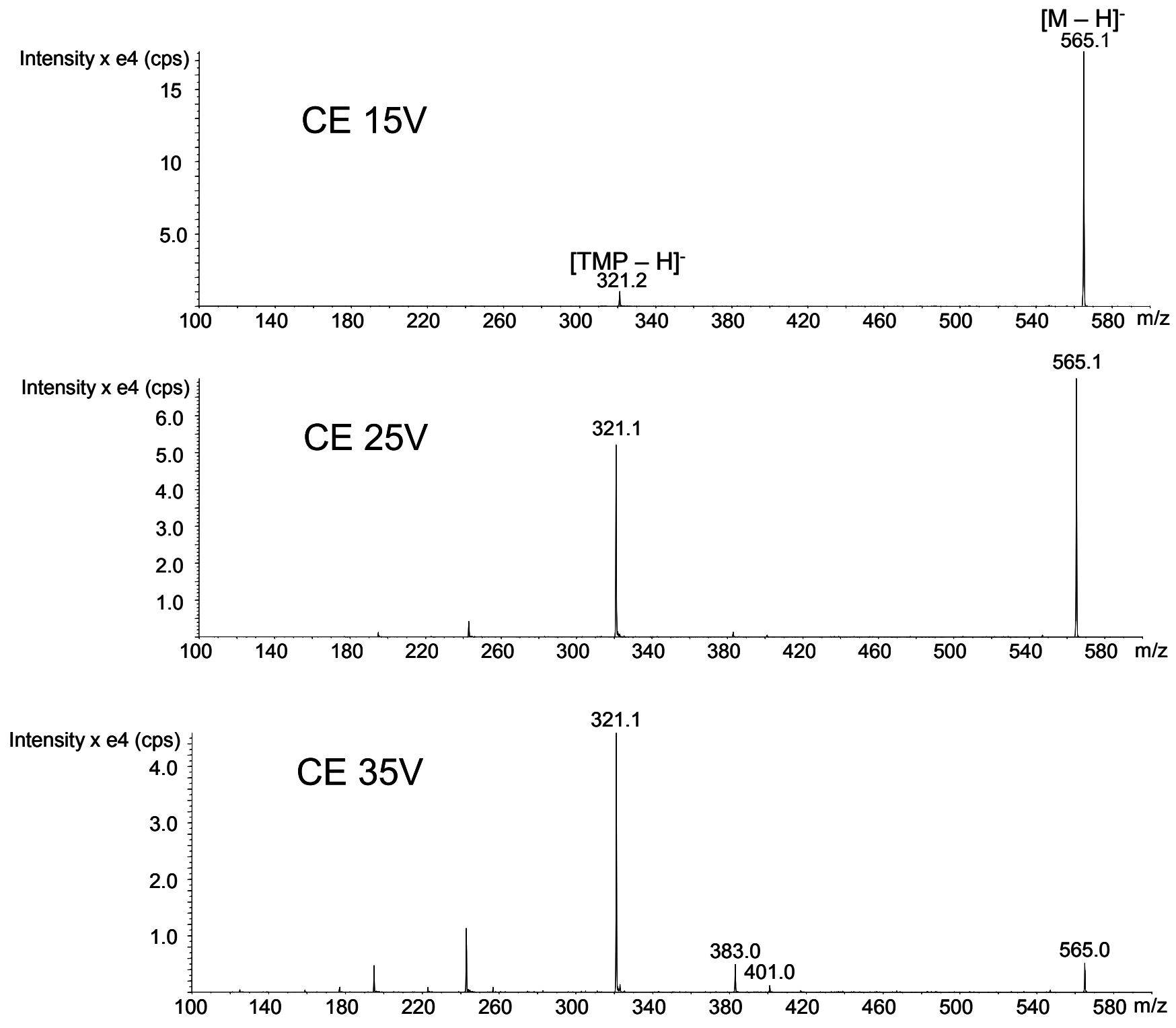


\section{dTDP- $\alpha-D-G I c p$}
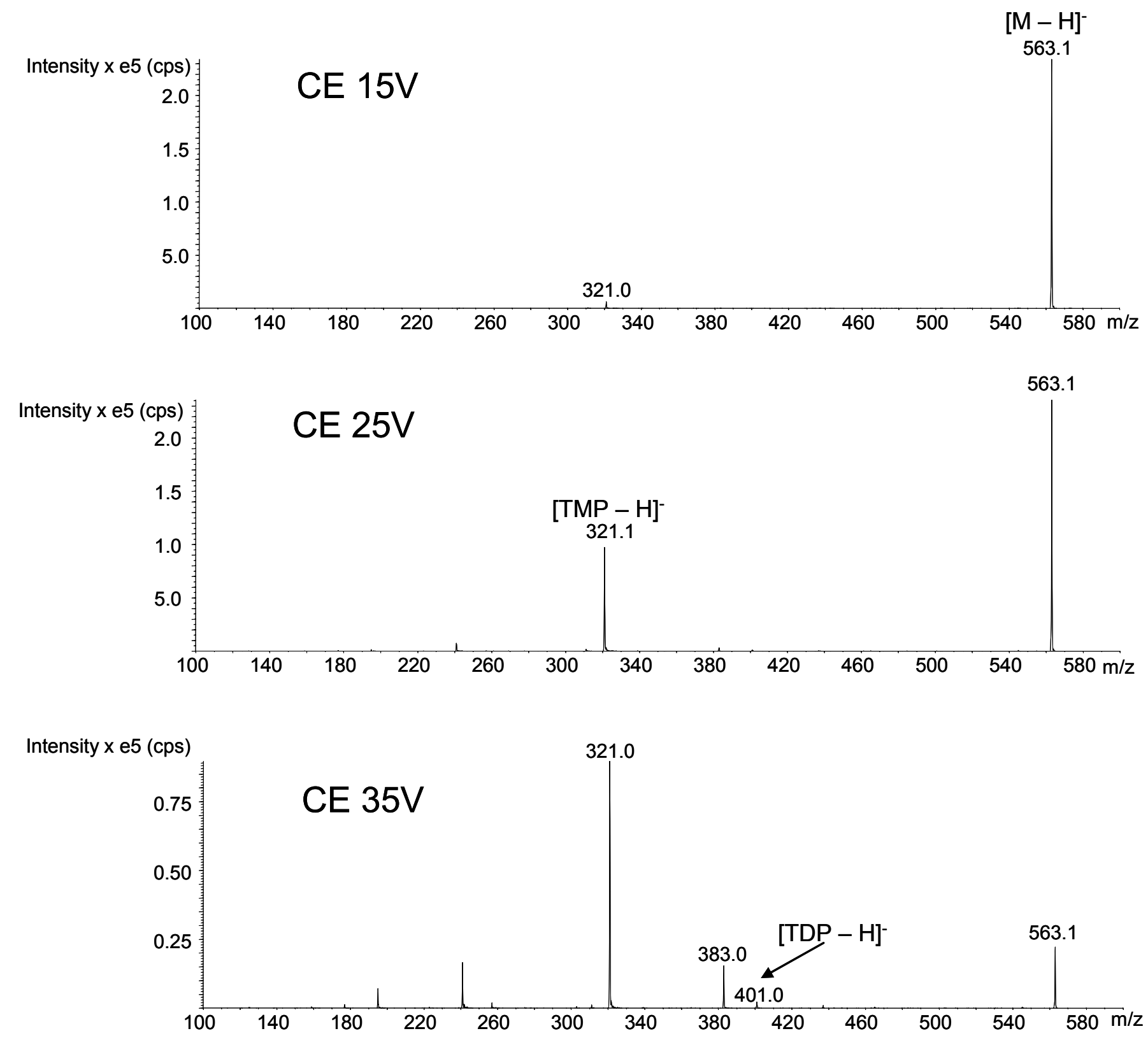


\section{UDP- $\alpha-D-G I c p$}
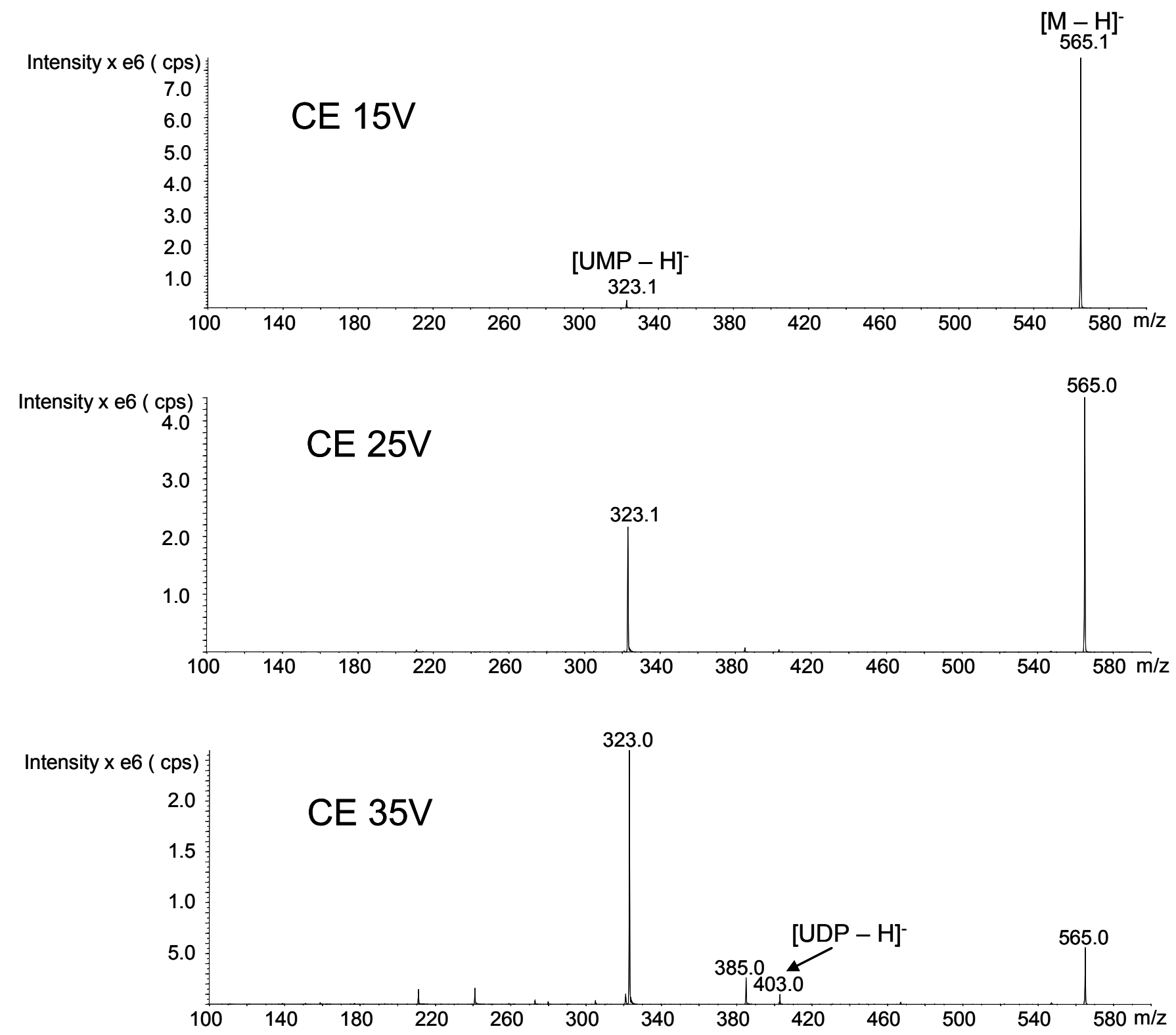


\section{UDP- $\alpha-D-M a n p$}
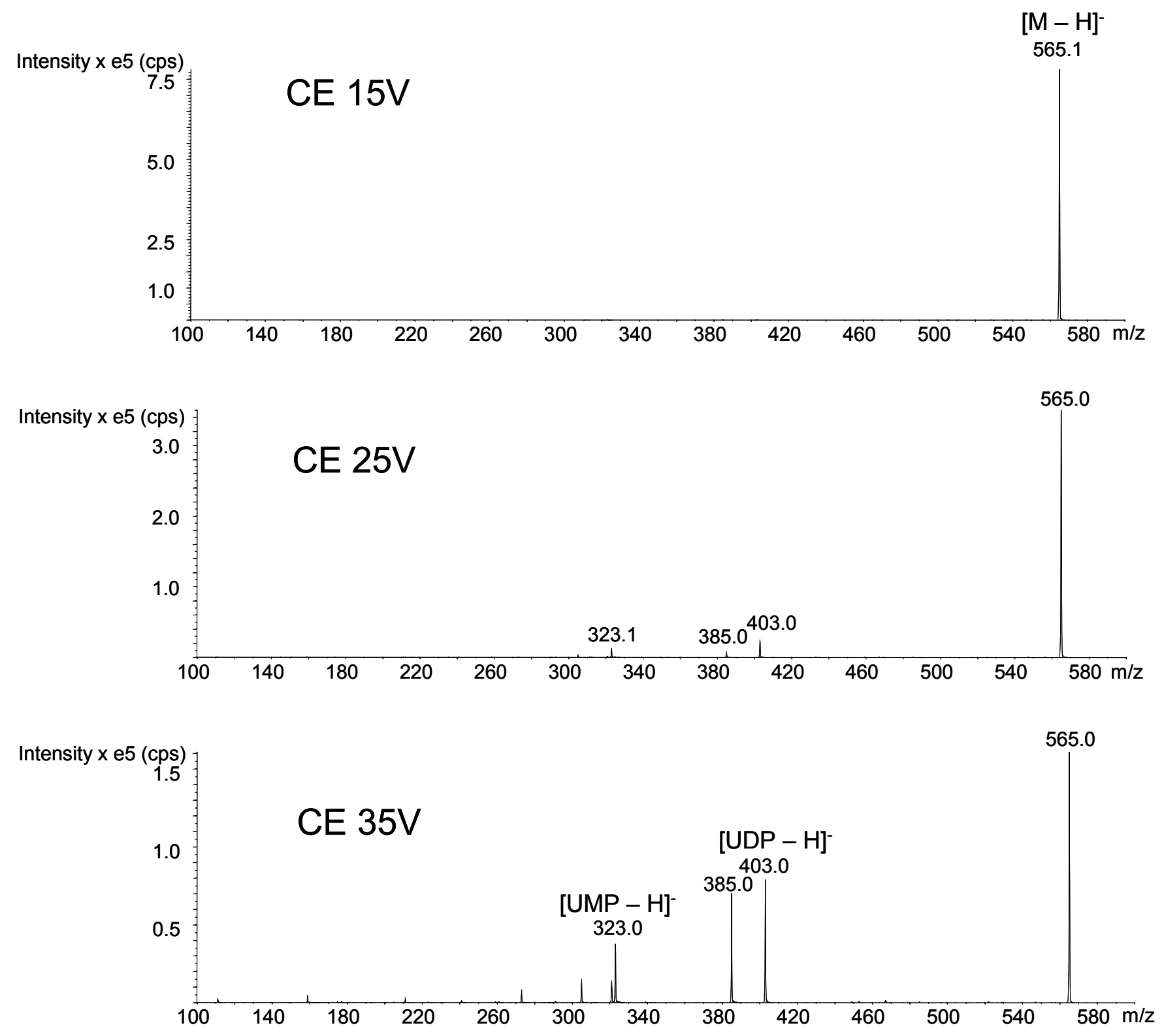


\section{Kinetic parameters with respect to $\alpha-D-G I c p-1-P$ and $\beta-L-A r a f-1-P$}

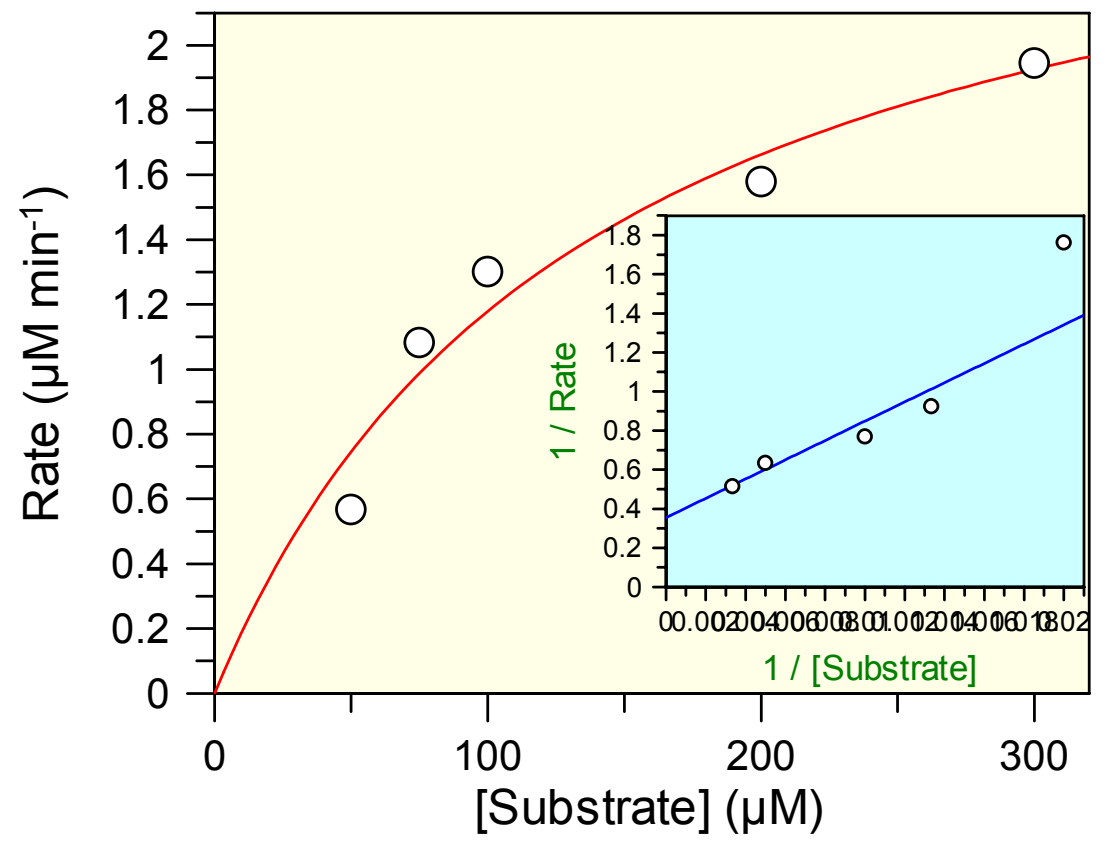

Figure S7. Michaelis-Menten and Lineweaver-Burk plots for Glc-1-P

Michaelis-Menton plot with inset Lineweaver-Burk plot demonstrating a $\mathrm{V}_{\max }$ of $2.8 \mu \mathrm{M} \min ^{-1}$ and a $\mathrm{K}_{\mathrm{m}}$ of $139 \mu \mathrm{M}$ with respect to $\alpha-\mathrm{D}-\mathrm{Glc} p-1-\mathrm{P}$. 


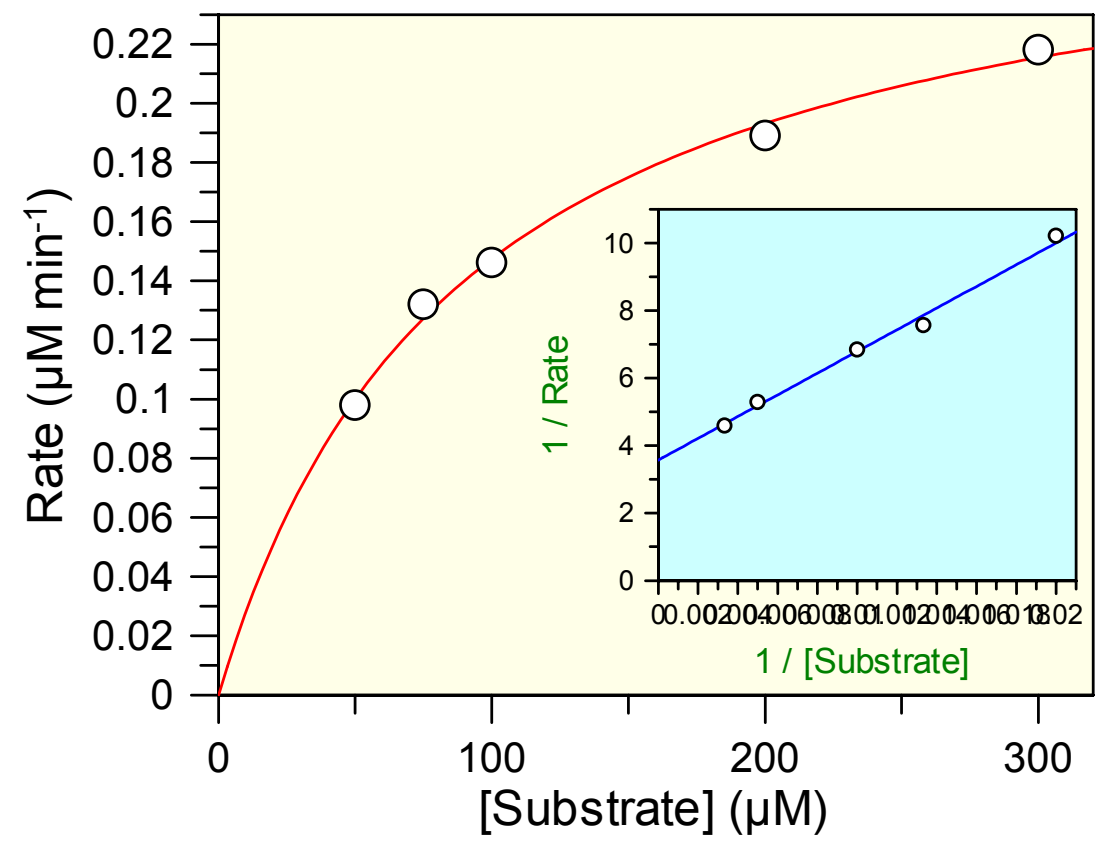

Figure S8. Michaelis-Menten and Lineweaver-Burk plots for Araf-1-P

Michaelis-Menton plot with inset Lineweaver-Burk plot demonstrating a $V_{\max }$ of $0.28 \mu \mathrm{M} \mathrm{min}^{-1}$ and a $\mathrm{K}_{\mathrm{m}}$ of $90.0 \mu \mathrm{M}$ with respect to $\beta$-L-Araf-1-P.

Table S2. Kinetic parameters for Cps2L with respect to $\alpha-D-G l c p-1-P$ and $\beta$ L-Araf-1-P

\begin{tabular}{lrr} 
Parameter & $\alpha$-D-Glc-1-P & $\beta$-L-Araf-1-P \\
\hline & & \\
$\mathrm{V}_{\max }\left(\mu \mathrm{M} \min ^{-1}\right)$ & 2.8175 & 0.2801 \\
$\mathrm{~K}_{\mathrm{m}}(\mu \mathrm{M})$ & 138.9024 & 90.0493 \\
$k_{\text {cat }}\left(\mathrm{min}^{-1}\right)$ & 27.6 & 0.00218 \\
$k_{\text {cat }} / \mathrm{K}_{\mathrm{m}}\left(\mu \mathrm{M}^{-1} \mathrm{~min}^{-1}\right)$ & 0.199 & 0.0000242
\end{tabular}

